\section{DiscoverSys \\ Published by DiscoverSys \\ Risk factors and novel prognostic score for predicting the 14-day mortality of severe traumatic brain injury patients}

\author{
Nyoman Golden ${ }^{1 *}$, Putu Eka Mardhika', Wayan Niryana', \\ I Made Sukarya ${ }^{2}$, I Putu Yuda Prabawa ${ }^{3}$
}

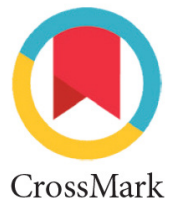

CrossMark

\section{ABSTRACT}

Introduction: The mortality of severe traumatic brain injury (TBI) is contributed by the severity of the head injury, associated trauma, and complication during treatment. This study aimed to develop a prognostic scoring system of risk factors that contribute to the 14day mortality of severe TBI.

Methods: This was a prospective cohort study including 105 severe TBI patients recruited consecutively from March to 0 ctober 2016. Multivariate analysis with logistic regression was performed to determine the most contributing risk factors. The validation of prognostic factor was performed with ROC, sensitivity and specificity analysis.
Result: There were five significant risk factors of 14-day mortality, which were age $>60$ years old (RR: 15.6, 95\% Cl: $1.88-129.95)$, hypoxia (RR: 17.78, 95\% Cl: 2.05 - 154.11), GCS 3 - 5 (RR: 34.71, 95\% Cl: 6.85 - 175.98), effacement of basal cistern (RR: 12.71, $95 \%$ Cl: $2.61-61.95)$, and traumatic subarachnoid hemorrhage (tSAH) (RR:7.57, 95\% Cl: 1.19 - 48.36). The prognostic score ranged from 0 to 6 with the best cut-off point of 1 . The best predictive AUC with ROC analysis was $0.817,81.2 \%$ of sensitivity, and $75.0 \%$ of specificity.

Conclusion: The proposed prognostic score has shown good predictive ability.

Keywords: mortality risk factor, prognostic score, severe traumatic brain injury, 14-days mortality

Cite This Article: Golden, N., Mardhika, P.E., Niryana, W., Sukarya, I.M., Prabawa, I.P.Y. 2020. Risk factors and novel prognostic score for predicting the 14-day mortality of severe traumatic brain injury patients. Intisari Sains Medis 11 (3): 1020-1028. D0l: 10.15562/ism. v11i3.831

${ }^{1}$ Neurosurgery Division, Department of Surgery, Faculty of Medicine, Universitas Udayana, Sanglah General Hospital, Bali, Indonesia

${ }^{2}$ Department of Surgery, Faculty of Medicine, Universitas Udayana, Sanglah General Hospital, Bali, Indonesia

${ }^{3}$ Department of Clinical Pathology, Faculty of Medicine, Universitas Udayana, Sanglah General Hospital, Bali, Indonesia

\section{*Corresponding to:} Nyoman Golden; Neurosurgery Division, Department of Surgery, Faculty of Medicine, Universitas Udayana, Sanglah General Hospital, Bali, Indonesia; nyoman_golden@yahoo.com

Received: 2020-09-29 Accepted: 2020-10-15 Published: 2020-10-26

\section{INTRODUCTION}

The management of patients with severe traumatic brain injury (TBI) requires expensive resources and a relatively long time of treatment. Even with adequate management, mortality and long-term morbidity are still high. Patients with head injury need to establish risk factors that contribute to the worsening of outcomes as early as possible. It should be done to provide appropriate, accurate and systematic actions and therapies immediately to produce a good prognosis. ${ }^{1,2}$ Further decisions regarding the management of severe TBI patients must involve the patient's family, so informed consent about patient outcomes requires adequate and accurate data. Predicting the outcome of severe TBI patients accurately is important for fund allocations, appropriate clinical decisions and realistic informed consent to the family.

Head injuries are expected to surpass other diseases as a major cause of death and disability in 2020. ${ }^{3}$ The number of head injury cases in the United States reaches 1.7 million cases each year with deaths reaching 52,000 people, and $10 \%$ of them are patients with severe TBI. ${ }^{4}$ In Indonesia, the mortality rate in all severity of head injuries ranges from $6.17 \%$ to $11.22 \%$, with deaths in severe TBI ranging from $25.23 \%$ to $37.14 \% .^{5}$ Internationally, mortality rate in severe TBI varies between $13 \%$ to $33.3 \%$. $^{6-8}$

The highest proportion of head injury mortality occurs $1-2$ weeks after the trauma, where $85 \%$ of deaths in severe TBI occur in the first 14 days after trauma. ${ }^{9}$ Several prognostic scores were made only by considering clinical factors of head injury severity without considering the effect of complications during treatment. ${ }^{10-12}$ Observation for 14 days can be done to assess the influence of head injury severity, accompanying trauma, and complications during treatment. ${ }^{13}$ Besides that, the prognostic assessment 14 days after trauma can also describe Glasgow Outcome Scale (GOS) within six months. ${ }^{14}$ Based on that, the authors were interested in developing a validated prognostic scoring system regarding risk factors for 14-day mortality in severe TBI patients.

\section{MATERIAL AND METHODS}

A prospective cohort study was conducted on 105 patients over the age of 6 years with severe TBI who came to the Emergency Care Unit of Sanglah General 
Table 1. Characteristic of subjects

\begin{tabular}{|c|c|c|}
\hline Variable & $\mathbf{N}$ & $\%$ \\
\hline \multicolumn{3}{|l|}{ 14-day follow up } \\
\hline Alive & 36 & 34.3 \\
\hline Dead & 69 & 65.7 \\
\hline \multicolumn{3}{|l|}{ Age } \\
\hline$>60$ years old & 17 & 16.2 \\
\hline$\leq 60$ years old & 88 & 83.8 \\
\hline \multicolumn{3}{|l|}{ Sex } \\
\hline Male & 87 & 16.2 \\
\hline Female & 18 & 83.8 \\
\hline \multicolumn{3}{|l|}{ Operation time } \\
\hline No operation & 79 & 75.2 \\
\hline$>4$ hours & 17 & 16.2 \\
\hline$\leq 4$ hours & 9 & 8.6 \\
\hline \multicolumn{3}{|l|}{ GCS on admission } \\
\hline $3-5$ & 61 & 58.1 \\
\hline $5-6$ & 44 & 41.9 \\
\hline \multicolumn{3}{|l|}{ ISS score } \\
\hline$\geq 30$ & 36 & 34.3 \\
\hline$<30$ & 69 & 65.7 \\
\hline \multicolumn{3}{|l|}{ Hypotension } \\
\hline Yes & 18 & 17.1 \\
\hline No & 87 & 82.9 \\
\hline \multicolumn{3}{|l|}{ Hypoxia } \\
\hline Yes & 31 & 29.5 \\
\hline No & 74 & 70.5 \\
\hline \multicolumn{3}{|l|}{ Pupil condition } \\
\hline Bilateral mydriasis & 20 & 19.0 \\
\hline Anisocore & 19 & 18.1 \\
\hline Isocore & 66 & 62.9 \\
\hline \multicolumn{3}{|l|}{ Pneumonia } \\
\hline Yes & 19 & 18.1 \\
\hline No & 86 & 81.9 \\
\hline \multicolumn{3}{|l|}{ Central hyperthermia } \\
\hline Yes & 6 & 5.7 \\
\hline No & 99 & 94.3 \\
\hline \multicolumn{3}{|l|}{ Midline shift } \\
\hline Yes & 56 & 53.3 \\
\hline No & 49 & 46.7 \\
\hline \multicolumn{3}{|l|}{ Midline shift (mm) } \\
\hline$\geq 5 \mathrm{~mm}$ & 35 & 33.3 \\
\hline$<5 \mathrm{~mm}$ & 21 & 20.0 \\
\hline \multicolumn{3}{|l|}{ Basal cistern effacement } \\
\hline Yes & 64 & 61.0 \\
\hline No & 41 & 39.0 \\
\hline \multicolumn{3}{|l|}{ Traumatic SAH } \\
\hline Yes & 32 & 30.4 \\
\hline No & 73 & 69.6 \\
\hline \multicolumn{3}{|l|}{ Epidural hematoma } \\
\hline Yes & 32 & 30.5 \\
\hline No & 73 & 69.5 \\
\hline \multicolumn{3}{|l|}{ Subdural hematoma } \\
\hline Yes & 42 & 40.0 \\
\hline No & 63 & 60.0 \\
\hline \multicolumn{3}{|l|}{ Intracerebral hematoma } \\
\hline Yes & 22 & 20.9 \\
\hline No & 83 & 79.1 \\
\hline Cerebral contusion & & \\
\hline Yes & 20 & 19.0 \\
\hline No & 85 & 81.0 \\
\hline
\end{tabular}

Hospital Denpasar between March and October 2016. Patients with severe TBI with a history of cerebrovascular disease, non-hemorrhagic stroke, hemorrhagic stroke, died before head CT scan was performed, suspected of alcohol intoxication, and patients with a history of pupillary reflex disorder were excluded from this study. All subjects in this study were managed with standard treatment protocol in our hospital. This study protocol had been approved by ethical committee in Sanglah General Hospital.

Eligible subjects were assessed for risk factors that predict the occurrence of death within 14 days. Based on the literature review, we found several important risk factors associated with the occurrence of death within 14 days in severe TBI patients. ${ }^{9}{ }^{13,15-19}$ Based on our previous observations, we found several important risk factors to be assessed for their effects on the occurrence of death, which were age, sex, GCS score on admission, hypotension, pupillary reflexes, operation time, ISS, pneumonia, central hyperthermia, and head CT scan appearance. All subjects received treatment in accordance with current neurosurgical therapy protocol.

All data were presented dichotomously. We performed a bivariate analysis (chi-square test on the significance limit of $a=0.05$ ) to assess the effect of risk factors on mortality within 14 days in severe TBI patients. Multivariate logistic regression was used to assess the influence of each risk factor on the occurrence of death. This analysis resulted as relative risk (RR) with $95 \%$ of Confidence Interval (CI) and a significance limit of less than 0.05 . The $\mathrm{RR}$ of significant risk factors were used as the basis for making prognostic scores. To assess the validity of the scores that have been made, the validity test consists of two stages, which were ROC analysis and assessment of sensitivity and specificity.

\section{RESULTS}

\section{Characteristic of subjects}

This study was conducted on severe TBI patients who came to the emergency department of Sanglah General Hospital from March 2016 to October 2016. In this period, 105 subjects were included consisting of 87 men $(82.8 \%)$ with an average age of 37.1 years old. Informed consent were obtained from all subject's closest relative since subjects were unable to give consents. Clinical evaluation of patients was performed after patients were resuscitated. Sixty-one subjects $(58.1 \%)$ had initial GCS 3 - 5, 39 subjects (37.1\%) had abnormal pupils, 18 subjects (17.1\%) had hypotension, 31 subjects (29.5\%) had hypoxia, and 36 subjects $(34.3 \%)$ had multi-trauma with ISS $\geq 30$. Twenty- 
Table 2. Bivariate analysis

\begin{tabular}{|c|c|c|c|c|c|}
\hline \multirow{2}{*}{ Variable } & \multicolumn{2}{|c|}{ Outcome } & \multirow{2}{*}{$\mathbf{R R}$} & \multirow{2}{*}{$95 \% \mathrm{Cl}$} & \multirow{2}{*}{ P-value } \\
\hline & Death & Alive & & & \\
\hline \multicolumn{6}{|l|}{ Age } \\
\hline$>60$ years old & $15(88.2)$ & $2(11.8)$ & \multirow{2}{*}{1.44} & \multirow{2}{*}{$1.13-1.83$} & \multirow{2}{*}{$0.033^{*}$} \\
\hline$\leq 60$ years old & $54(61.4)$ & $34(36.6)$ & & & \\
\hline \multicolumn{6}{|l|}{ Sex } \\
\hline Male & $54(62.1)$ & $33(37.9)$ & \multirow{2}{*}{0.75} & \multirow{2}{*}{$0.57-0.97$} & \multirow{2}{*}{0.084} \\
\hline Female & $15(83.3)$ & $3(16.7)$ & & & \\
\hline \multicolumn{6}{|l|}{ Operation time } \\
\hline$>4$ hours & $8(47.1)$ & $9(52.9)$ & \multirow{2}{*}{0.68} & \multirow{2}{*}{$0.40-1.15$} & \multirow{2}{*}{0.077} \\
\hline$\leq 4$ hours & $61(69.3)$ & $27(30.7)$ & & & \\
\hline \multicolumn{6}{|l|}{ Hypotension } \\
\hline Yes & $16(88.9)$ & $2(11.1)$ & 146 & $115-185$ & $0.023 *$ \\
\hline No & $53(60.9)$ & $34(39.1)$ & 1.46 & $1.15-1.85$ & \\
\hline Hypoxia & & & & & \\
\hline Yes & $28(90.3)$ & $3(9.7)$ & 162 & $120 \quad 20$ & 0001 * \\
\hline No & $41(55.4)$ & $33(44.6)$ & 1.63 & $1.29-2.06$ & $0.001^{n}$ \\
\hline GCS on admission & & & & & \\
\hline $3-5$ & $56(91.8)$ & $5(8.2)$ & 211 & $106 \quad 402$ & $-0001 *$ \\
\hline $6-8$ & $13(29.5)$ & $31(70.5)$ & 3.11 & $1.96-4.93$ & $<0.001^{2}$ \\
\hline Pupillary anisocore & & & & & \\
\hline Yes & $12(63.2)$ & $7(36.8)$ & 0.95 & $066-130$ & 0795 \\
\hline No & $57(66.3)$ & $29(33.7)$ & 0.95 & $0.66-1.39$ & 0.795 \\
\hline Bilateral pupillary $n$ & & & & & \\
\hline Yes & $19(95.0)$ & $1(5.0)$ & 162 & $132-198$ & $0002 *$ \\
\hline No & $50(58.8)$ & $35(41.2)$ & & & \\
\hline ISS score & & & & & \\
\hline$\geq 30$ & $33(91.7)$ & $3(8.3)$ & 176 & $127 \quad 225$ & C0001* \\
\hline$<30$ & $36(52.2)$ & $33(47.8)$ & 1.76 & $1.37-2.25$ & $<0.001^{*}$ \\
\hline Pneumonia & & & & & \\
\hline Yes & $11(57.9)$ & $8(42.1)$ & 006 & $057 \quad 120$ & 0428 \\
\hline No & $58(67.4)$ & $28(32.6)$ & 0.86 & $0.57-1.29$ & 0.428 \\
\hline Central hypertherm & & & & & \\
\hline Yes & $4(66.7)$ & $2(33.3)$ & 102 & $0.57-182$ & 0060 \\
\hline No & $65(65.7)$ & $34(34.3)$ & & $0.57-1.82$ & 0.960 \\
\hline Midline shift $\geq 5 \mathrm{mi}$ & & & & & \\
\hline Yes & $26(74.3)$ & $9(25.7)$ & 121 & $092-158$ & 0191 \\
\hline No & $43(61.4)$ & $27(38.6)$ & & & \\
\hline Basal cistern effacen & & & & & \\
\hline Yes & $55(85.9)$ & $9(14.1)$ & 252 & $163-389$ & $<0001 *$ \\
\hline No & $14(34.1)$ & $27(65.9)$ & 2.52 & $1.63-3.89$ & $<0.001^{x}$ \\
\hline Traumatic SAH & & & & & \\
\hline Yes & $29(90.6)$ & $3(9.4)$ & 165 & $121 \quad 200$ & - $0001 *$ \\
\hline No & $40(54.8)$ & $33(45.2)$ & 1.65 & $1.31-2.09$ & $<0.001$ \\
\hline Epidural hematoma & & & & & \\
\hline Yes & $17(53.1)$ & $15(46.9)$ & 075 & $0.52-107$ & 0.072 \\
\hline No & $52(71.2)$ & $21(28.8)$ & 0.75 & & \\
\hline Subdural hematom & & & & & \\
\hline Yes & $33(78.6)$ & $9(21.4)$ & 130 & $105 \quad 170$ & $0023 *$ \\
\hline No & $36(57.1)$ & $27(42.9)$ & 1.38 & $1.05-1.79$ & $0.023^{\star}$ \\
\hline Intracerebral hemat & & & & & \\
\hline Yes & $19(86.4)$ & $3(13.6)$ & 143 & $113-182$ & $0020 *$ \\
\hline No & $50(60.2)$ & $33(39.8)$ & 1.43 & $1.13-1.82$ & $0.022^{*}$ \\
\hline Cerebral contusion & & & & & \\
\hline Yes & $15(75.0)$ & $5(25.0)$ & 118 & 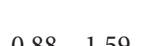 & 0.32 \\
\hline No & $54(63.5)$ & $31(36.5)$ & 1.18 & $0.88-1.59$ & 0.331 \\
\hline
\end{tabular}

*: statistically significant six subjects underwent surgery with 22 subjects were operated 4 hours after admission. Nineteen subjects experienced pneumonia during treatment (18.1\%) and six had central hyperthermia (5.7\%). Based on the head CT scan appearance, there were 35 subjects (33.3\%) with $5 \mathrm{~mm}$ of midline shift, 64 subjects $(61.0 \%)$ had basal cistern effacement, and 32 subjects (30.4\%) had traumatic SAH (tSAH). The study subjects were followed up for 14 days. Sixtynine subjects died (65.71\%) and 36 subjects (34.3\%) were alive. In summary, the overall characteristics of the subjects can be seen in Table 1 .

\section{Analysis of clinical factors}

Bivariate analysis showed 10 significant risk factors for mortality in 14 days. They were age above 60 years old (RR: 1.44, 95\% CI: 1.13 - 1.83), hypotension (RR: 1.46, 95\% CI: 1.15 - 1.85), hypoxia (RR: $1.63,95 \%$ CI: $1.29-2.06$ ), GCS on admission 3 - 5 (RR: 3.11, 95\% CI: 1.96 - 4.93), bilateral pupillary mydriasis (RR: 1.62, 95\% CI: 1.32 - 1.98), ISS (RR: $1.76,95 \%$ CI: $1.37-2.25$ ), basal cistern effacement (RR: 2.52, 95\% CI: 1.63 3.89), tSAH (RR: $1.65,95 \%$ CI: $1.32-2.13$ ), SDH (RR: 1.38, 95\% CI: 1.05 - 1.79), and ICH (RR: 1.43, 95\% CI: $1.13-1.82$ ). The overall results of bivariate analysis can be seen in Table 2 .

Significantly associated variables in the bivariate analysis were analyzed with multivariate logistic regression. Based on multivariate analysis, there were five statistically significant risk factors for mortality in 14 days. They were age $>60$ years old (RR: 15.6, 95\% CI: 1.88 - 129.95), hypoxia (RR: 17.78, 95\% CI: 2.05 - 154.11), GCS score on admission 3 - 5 (RR: 34.71, 95\% CI: 6.85 - 175.98), basal cistern effacement (RR: 12.71, 95 \% CI: 2.61 61.95), and tSAH (RR: 7.57, 95\% CI: 1.19 - 48.36). The results of the multivariate analysis can be seen in Table 3.

\section{Scoring system}

Prognosis scores are made by giving different weights to each variable based B value and SE from logistic regression analysis. The tSAH variable with the smallest $\mathrm{B} / \mathrm{SE}$ ratio was given a score of 1 , while the other variables were scored according to their respective ratio, as shown in Table 4 and Table 5. The score can be called good because the area under the curve value is more or equal to 0.7 (AUC 0.817), as seen in Figure 1. Based on the ROC analysis the best cut point can be obtained, namely 1 so that patients with more than 1 scores were categorized as high risk and those who were less than 1 were categorized as low risk. The sensitivity of the severe TBI prognostic score was $81.2 \%$ and the specificity was $75.0 \%$. The mortality risk from each total score 
Table 3. Multivariate analysis

\begin{tabular}{lccc}
\hline Variable & RR & $\mathbf{9 5 \%} \mathbf{C l}$ & P-value \\
\hline Age & 15.6 & $1.88-129.95$ & $0.011^{\star}$ \\
Hypotension & 1.45 & $0.09-23.59$ & 0.795 \\
Hypoxia & 17.78 & $2.05-154.11$ & $0.009^{*}$ \\
GCS on admission & 34.71 & $6.85-175.98$ & $<0.001^{*}$ \\
Bilateral mydriasis & 5.26 & $0.31-88.12$ & 0.25 \\
ISS score & 5.13 & $0.40-65.57$ & 0.208 \\
Basal cistern effacement & 12.71 & $2.61-61.95$ & $0.002^{\star}$ \\
Traumatic SAH & 7.57 & $1.19-48.36$ & $0.032^{\star}$ \\
Subdural hematoma & 3.13 & $0.56-17.47$ & 0.194 \\
Intracerebral hematoma & 1.36 & $0.11-16.42$ & 0.811 \\
\hline
\end{tabular}

*: statistically significant

Table 4. Generating prognostic score

\begin{tabular}{lccccc}
\hline \multicolumn{1}{c}{ Variable } & B & SE & B/SE & (B/SE)/2.139 & Conversion \\
\hline GCS on admission & 3.547 & 0.828 & 4.283 & 2.002 & 2 \\
Hypoxia & 2.878 & 1.102 & 2.611 & 1.220 & 1 \\
Age & 2.749 & 1.081 & 2.543 & 1.188 & 1 \\
$\begin{array}{l}\text { Basal cistern } \\
\text { effacement }\end{array}$ & 2.543 & 0.808 & 3.147 & 1.471 & 1 \\
\begin{tabular}{l} 
Traumatic SAH \\
\hline
\end{tabular} & 2.024 & 0.946 & 2.139 & 1.000 & 1 \\
\hline
\end{tabular}

Table 5. Prognostic scoring

\begin{tabular}{|c|c|c|c|c|}
\hline Variable & P-value & $95 \% \mathrm{Cl}$ & OR & Score \\
\hline \multicolumn{5}{|l|}{ GCS on admission } \\
\hline GCS 3-5 & \multirow{2}{*}{$<0.001$} & \multirow{2}{*}{$6.85-175.98$} & \multirow{2}{*}{34.7} & 2 \\
\hline GCS 6-8 & & & & 0 \\
\hline \multicolumn{5}{|l|}{ Hypoxia } \\
\hline Yes & \multirow{2}{*}{0.009} & \multirow{2}{*}{$2.05-154.11$} & \multirow{2}{*}{17.8} & 1 \\
\hline No & & & & 0 \\
\hline \multicolumn{5}{|l|}{ Age } \\
\hline$>60$ years old & \multirow{2}{*}{0.011} & \multirow{2}{*}{$1.88-129.95$} & \multirow{2}{*}{15.6} & 1 \\
\hline$\leq 60$ years old & & & & 0 \\
\hline \multicolumn{5}{|c|}{ Basal cistern effacement } \\
\hline Yes & \multirow{2}{*}{0.002} & \multirow{2}{*}{$2.61-61.95$} & \multirow{2}{*}{12.7} & 1 \\
\hline No & & & & 0 \\
\hline \multicolumn{5}{|l|}{ Traumatic SAH } \\
\hline Yes & \multirow{2}{*}{0.032} & \multirow{2}{*}{$1.19-48.36$} & \multirow{2}{*}{7.6} & 1 \\
\hline No & & & & 0 \\
\hline
\end{tabular}

can be seen in Table 6. The higher in total score increases the mortality risk of severe TBI within 14 days.

\section{DISCUSSION}

It is important to predict the outcome of severe TBI patients accurately for funding allocation, making appropriate clinical decisions and giving realistic informed consent to the family. The presence of a validated prognosis system can provide us a prediction of good prognosis so more aggressive therapy can be carried out. The prognostic factors in this study were chosen based on several previous studies. ${ }^{16-19}$ We found that several variables could be prognostic factors for outcomes of severe TBI patients. They were age, bilateral mydriasis pupil, hypotension, hypoxia, GCS score, ISS, basal cistern effacement, presence of $\mathrm{tSAH}, \mathrm{SDH}$ and $\mathrm{ICH}$. Among these meaningful variables, five prognostic factors most significantly affected the 14-day mortality of patients with severe TBI. They were age over 60 years, GCS $3-5$, hypoxia, presence of tSAH, and basal cistern effacement.

Age over 60 has greater risk of death in severe TBI patients. This is consistent with findings from several studies that stated age is an independent predictor of the outcome of head injury patients. ${ }^{20-23}$ In a study conducted by Heiskenen, it was found that older patients had worse prognosis or outcome, especially at the age above 60 years old..$^{24}$ This could happen because of the presence of co-morbidities in line with increasing age, reduced brain recovery capacity, decreased blood vessel elasticity, and brain atrophy, which results in susceptibility of dura blood vessels damage after trauma. ${ }^{22}$

In hypoxic conditions, there is a failure of energy production, inhibition of oxidative phosphorylation, decreased ATP production, failure of $\mathrm{Na}+/ \mathrm{K}+$ ATPase active transport which triggers influx sodium and efflux potassium, and opening $\mathrm{Ca} 2+$ channels resulting in massive calcium influx. Calcium accumulation in the cell will cause activation of phospholipase and proteolysis, which triggers the hydrolysis of phospholipids membrane and increased free fatty acid. This will cause irreversible damage to cell membranes, and will eventually result in cerebral edema and increased ICP. $^{25,26}$ This study found that hypoxia is a strong prognostic factor associated with severe TBI patient outcomes. This is consistent with previous studies that state prehospital hypoxia significantly increases the odds ratio of mortality in patients who suffered severe TBI. ${ }^{27-29}$

Low GCS reflects a greater degree of brain damage. In this study, it was found that low GCS score (GCS $3-5)$ is a strong independent risk 


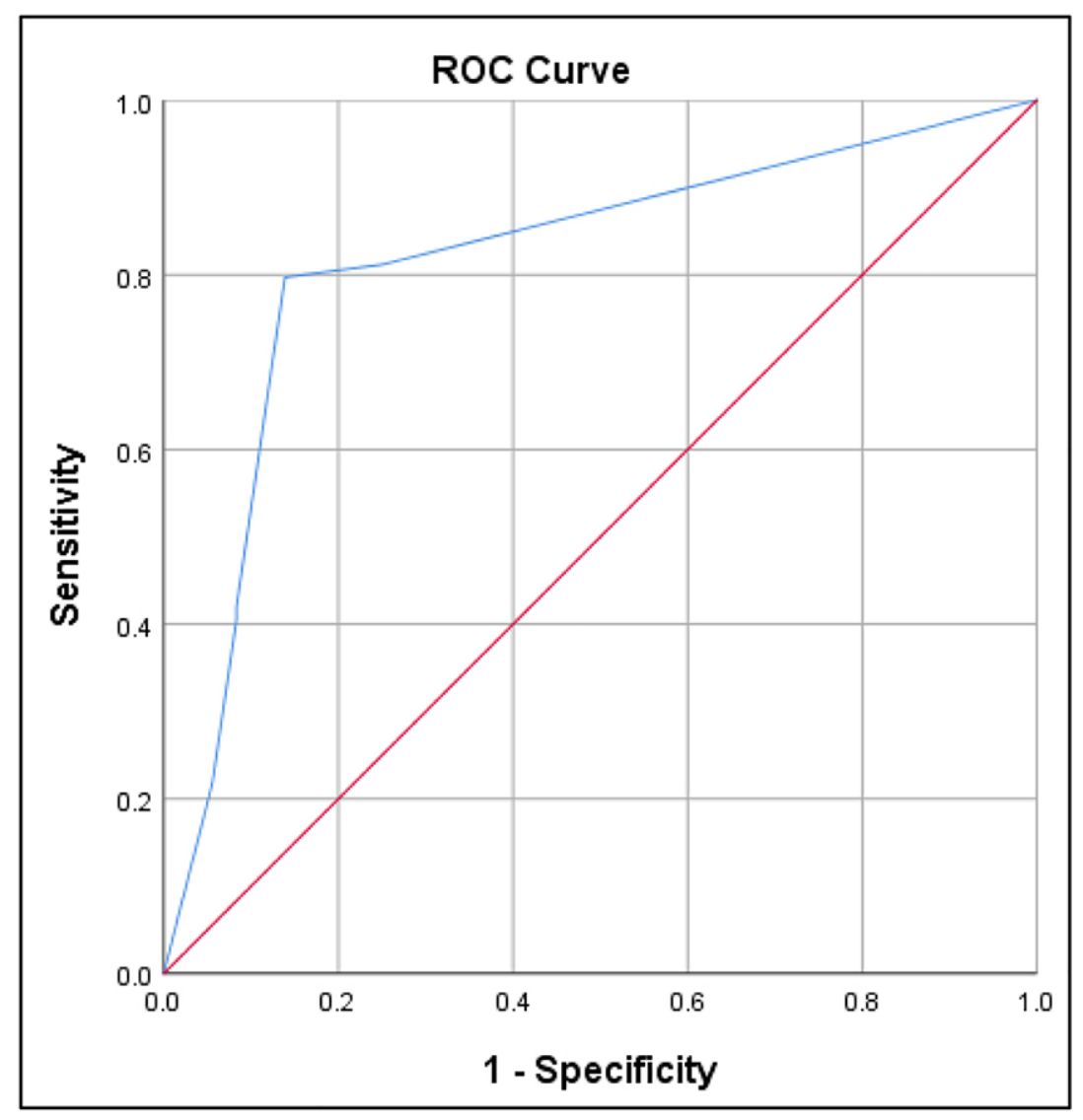

Figure 1. ROC analysis of the prognostic score of 14-day mortality in severe TBI patients. AUC: 0.817 , best cut-off point: 1, sensitivity: $81.2 \%$, and specificity: $75.0 \%$.

Table 6. Mortality risk of each total score

\begin{tabular}{ccccc}
\hline Score & Constanta & Coefficient & Y & Mortality risk \\
\hline 1 & -0.562 & 0.834 & 0.272 & $56.75 \%$ \\
2 & -0.562 & 0.834 & 1.106 & $75.04 \%$ \\
3 & -0.562 & 0.834 & 1.940 & $87.43 \%$ \\
4 & -0.562 & 0.834 & 2.774 & $93.93 \%$ \\
5 & -0.562 & 0.834 & 3.608 & $97.36 \%$ \\
6 & -0.562 & 0.834 & 4.462 & $98.83 \%$ \\
\hline
\end{tabular}

$\mathrm{Y}=0.562+0.834 \mathrm{x}$ total score; Mortality risk $(\mathrm{P})=1 /(1+\exp (-\mathrm{y})) \times 100 \%$

factor for the incidence of death within 14 days of severe TBI patients $(p=0.002)$. Low GCS is a risk factor that is almost always present in each study. It indicates the significance of this risk factor for the outcome of head injury patients. ${ }^{1,18,30-35}$

Compression of the basal cistern is an indicator of increased ICP. Increased intracranial pressure will cause a decrease of blood flow to the brain, which in turn will cause damage to brain tissue. Basal cistern compression on CT scan is a poor predictor of outcome in severe TBI patients. In this study, we obtained basal cistern effacement as an independent risk factor of mortality within 14 days in patients with severe TBI. This is consistent with the study by Tjahjadi et al. that reported basal cistern compression was the most dominant variable in predictors of mortality in severe TBI patients. ${ }^{15} \mathrm{~A}$ higher degree of basal cistern in severe TBI patients results in worse outcomes. ${ }^{36}$ In this study, we found that most of the patients presented with complete obliteration.

Traumatic SAH is one of the predictors of poor outcome in severe TBI patients. Traumatic SAH can induce secondary vasospasm and cerebral ischemia, which results in the worsening of outcomes. ${ }^{37-39}$ Vasospasm that occurs in tSAH causes cerebral edema, which is one of the factors that increases ICP. Besides that, the presence of SAH shows that the mechanism of trauma tends to be caused by acceleration-deceleration forces that have the potential to cause extensive brain damage. ${ }^{40}$ This study found that $\mathrm{tSAH}$ is an independent risk factor for mortality in 14 days of patients with severe TBI. This is in line with previous studies that found head injury patients with a tSAH showed significantly higher mortality. ${ }^{41,42}$ In addition, the presence of tSAH in severe TBI patients was an independent risk factor for poor outcome. ${ }^{17,43,44}$ The extent and location of SAH also influence the increase of ICP and the outcome. ${ }^{45}$ In this study, most of the study subjects showed extensive SAH appearance (grades 3 and 4 according to Fisher Scale for SAH Grading on Admission CT Scan). ${ }^{46}$

\section{CONCLUSION}

This prognostic scoring had a good predictive ability because the area under the curve value in the ROC analysis was more or equal to 0.7 (AUC 0.817 ), with a sensitivity level of $81.2 \%$ and a specificity of $75.0 \%$. This prognostic score is expected to provide more realistic informed consent to the patient's family, improved clinical decision making and funding allocation, especially in developing countries where the system and health facilities are still lacking.

\section{CONFLICT OF INTEREST}

The authors declare that they have no conflict of interest.

\section{FUNDING}

There was no sponsorship regarding this research.

\section{AUTHORS CONTRIBUTION}

All authors contributed to the study conception and design. Material preparation, data collection 
and analysis were performed by NG, MS, PEM, WN, and PYP. The first draft of the manuscript was written by PEM and all authors commented on previous versions of the manuscript. All authors read and approved the final manuscript.

\section{REFERENCES}

1. Golden N, Niryana W, Mahadewa TGB, Maliawan S, Chandra A. Two different approaches in obtaining head computerized tomography scan in minor head injuries. $J$ Neurol Res. 2013; 3: 114 - 12. DOI: 10.4021/jnr225w.

2. Andriessen TM, et al. Epidemiology, severity classification, and outcome of moderate and severe traumatic brain injury: a prospective multicenter study. $J$ Neurotrauma. 2011; 28(10): 2019 - 31. DOI: 10.1089/neu.2011.2034.

3. Finfer SR, Cohen J. Severe traumatic brain injury. Resuscitation. 2001; 48(1): 77 - 90

4. Faul M, Xu L, Wald MW, Coronado VG. Traumatic brain injury in the United States: Emergency department visits, hospitalization and death 2002 - 2006. US Department of Health Centers for Disease and Prevention National Center for Injury Prevention and Control. http://www.cdc.gov/ TraumaticBrainInjury.2010 (2010).

5. Wahyuhadi J, Suryaningtyas W, Susilo RI. Pedoman Tatalaksana Cidera Otak (Guideline for Management of Traumatic Brain Injury). Tim Neurotrauma RSU dr. Soetomo FK Universitas Airlangga Surabaya. 2007

6. Martins ET, et al. Mortality in severe traumatic brain injury: a multivariated analysis of 748 Brazilian patients from Flarianopolis City. J Trauma. 2009; 67(1): 85 - 90. DOI: 10.1097/TA.0b013e318187acee.

7. Gerber LM, Chiu YL, Carney N, Harti R, Ghajar J. Marked reduction in mortality in patients with severe traumatic brain injury. J Neurosurg. 2013; 119(6): 1583 - 1590. DOI: 10.3171/2013.8.JNS13276.

8. Jusuf WRA, Prasetyo E, Oley MC. Correlation between full outline responsiveness score and glasgow coma scale for severe head injury patients at Prof. dr. R. D. Kandou General Hospital, Manado-Indonesia. Bali Med J. 2012; 1(2): $71-73$.

9. Roberts I, et al. Effect of intravenous corticosteroids on death within 14 days in 10008 adults with clinically significant head injury (MRC CRASH trial): randomised placebo-controlled trial. Lancet. 2004; 364(9442): 1321 - 8. DOI: 10.1016/S0140-6736(04)17188-2.

10. Perel $\mathrm{P}$, et al. Predicting outcome after traumatic brain injury: practical prognostic models based on large cohort of international patients. BMJ. 2008; 336(7641): $425-429$. DOI: $10.1136 / \mathrm{bmj} .39461 .643438 .25$.

11. Steyerberg EW, et al. Predicting outcome after traumatic brain injury: development and international validation of prognostic scores based on admission characteristic. PLoS Med. 2008; 5(8): discussion e165. DOI: 10.1371/journal. pmed.0050165.

12. Gomez PA, et al. Validation of a prognostic score for early mortality in severe head injury cases. J Neurosurg. 2014; 121(6): 1314 - 22. DOI: 10.3171/2014.7.JNS131874.

13. Woratyla SP, Morgan AS, Mackay L, Bernstein B, Barba C. Factor associated with early onset pneumonia in the severely brain-injured patient. Conn Med. 1995; 59(11): $643-7$.

14. Perel P, Edwards P, Shakur H, Roberts I. Use of the Oxford Handicap Scale at hospital discharge to predict Glasgow Outcome Scale at 6 months in patients with traumatic brain injury. BMC Med Res Methodol. 2008; 8: 72. DOI: 10.1186/1471-2288-8-72.
15. Tjahjadi M, Arifin MZ, Gill AS, Faried A. Early mortality predictor of severe traumatic brain injury: a single center study of prognostic variables based on admission characteristics. The Indian J Neurotrauma. 2013; 10(1): 3 8. DOI: $10.1016 /$ j.ijnt.2013.04.007.

16. Moppett IK. Traumatic brain injury: assessment, resuscitation, and early management. Br J Anaesth. 2007; 99(1): 18 - 31. DOI: 10.1093/bja/aem128.

17. Murray GD, et al. The European Brain Injury Consortium Survey of head injuries. Acta Neurochir (Wien). 1999; 141(3): $223-236$.

18. Werner C, Engelhard K. Pathophysiology of traumatic brain injury. Br J Anaesth. 2007; 99(1): 4 - 9. DOI: 10.1093/ bja/aem 131.

19. Wright DW, et al. Gender differences in neurological emergencies part II: a consensus summary and research agenda on traumatic brain injury. Acad Emerg Med. 2014; 21(12): 1414 - 20. DOI: 10.1111/acem.12532 (2014).

20. Signorini DF, Andrews PJ, Jones PA, Wardlaw JM, Miller JD. Predicting survival using simple clinical variables: a case study in traumatic brain injury. J Neurol Neurosurg Psychiatry. 1999; 66(1): 20 - 25.

21. Mosenthal AC, et al. Isolated traumatic brain injury: age is an independent predictor of mortality and early outcome. $J$ Trauma. 2002; 52(5): 907 - 911.

22. Hukkelhoven CW, et al. Patient age and outcome following severe traumatic brain injury: an analysis of 5600 patients. J Neurosurg. 2003; 99(4): 666 - 673. DOI: 10.3171/ jns.2003.99.4.0666.

23. Maas AI, et al. Prognostic value of computerized tomography scan characteristics in traumatic brain injury: results from the IMPACT study. J Neurotrauma. 2007; 24(2): 303 - 314. DOI: 10.1089/neu.2006.0033.

24. Heiskanen O, Sipponen P. Prognosis of severe brain injury. Acta Neurol Scand. 1970; 46(3): 343 - 8. DOI: 10.1111/ j.1600-0404.1970.tb05798.x

25. Doyle KP, Simon RP, Stenzel-Poore MP. Mechanisms of ischemic brain damage. Neuropharmacology. 2008; 55(3): 310 - 318. DOI: 10.1016/j.neuropharm.2008.01.005.

26. Yajima $\mathrm{D}$, et al. The relationship between cell membrane damage and lipid peroxidation under the condition of hypoxia-reoxygenation: analysis of the mechanism using antioxidants and electron transport inhibitors. Cell Biochem Funct. 2009; 27(6): 338 - 343. DOI: 10.1002/cbf.1578.

27. Chesnut RM, et al. Early indicators of prognosis in severe traumatic brain injury. J Neurotrauma. 2000; 17: 557 - 627.

28. Chi JH, et al. Prehospital hypoxia affects outcome in patients with traumatic brain injury: a prospective multicenter study. J Trauma. 2006; 61(5): 1134 - 1141. DOI: 10.1097/01.ta.0000196644.64653.d8.

29. Brain Trauma Foundation Guidelines for The Management of Severe Traumatic Brain Injury. 2007; Mary Ann Liebert: New York.

30. Hsiang JN, Yeung T, Yu AL, Poon WS. High-risk mild head injury. J Neurosurg. 1997; 87(2): 234 - 8 .DOI: $10.3171 /$ jns.1997.87.2.0234.

31. Oertel $\mathrm{M}$, et al. Progressive hemorrhage after head trauma: predictors and consequences of the evolving injury. J Neurosurg. 2002; 96(1): 109 - 116. DOI: 10.3171/ jns.2002.96.1.0109.

32. Mizraji R, et al. Brain death epidemiology in Uruguay and utilization of the Glasgow coma score in acute brain injured patients as a predictor of brain death. Transplant Proc. 2009; 41(8): 3489 - 91. DOI: 10.1016/j.transproceed.2009.09.008.

33. Petroni $\mathrm{G}$, et al. Early prognosis of severe traumatic brain injury in urban argentinian trauma center. J Trauma. 2010; 68(3): 564 - 570. DOI: 10.1097/TA.0b013e3181celeed. 
34. Ting HW, Chen MS, Hsieh YC, Chan CL. Good mortality prediction by Glasgow Coma Scale for neurosurgical patients. J Chin Med Assoc. 2010; 73(3): 139 - 143. DOI: 10.1016/S1726-4901(10)70028-9.

35. Saini NS, Rampal V, Dewan Y, Grewal SS. Factors predicting outcome in patients with severe head injury: multivariate analysis. The Indian J Neurotrauma. 2012; 9(1), 45 - 48; 10.1016/j.ijnt.2012.04.009 (2012).

36. Liu HM, Tu YK, Su CT. Changes of brainstem and perimesenchepalic cistern: dynamic predictor of outcome in severe head injury. J Trauma. 1995; 38(3): 330 - 333.

37. Harders A, Kakarieka A, Braakman R. Traumatic subarachnoid hemorrhage and its treatment with nimodipine. German tSAH Study Group. J Neurosurg. 1996; 85(1): 82 - 89. DOI: 10.3171/jns.1996.85.1.0082.

38. Zurynski YA, Dorsch NW. A review of cerebral vasospasm. Part IV. Post-traumatic vasospasm. J Clin Neurosci. 1998; 5(2): $146-154$.

39. Aminmansour B, Ghorbani A, Sharifi D, Shemshaki H, Ahmadi A. Cerebral vasospasm following traumatic subarachnoid hemorrhage. J Res Med Sci. 2009; 14(6): 343 -348 .

40. Splitz WU, Splitz DJ. Splitz and Fisher's Medicolegal Investigation of Death. Charles C Thomas Publisher; 2006.

41. Kakarieka A, Braakman R, Schakel EH. Clinical significance of finding of subarachnoid blood on CT scan after head injury. Acta Neurochir(Wien). 1994; 129(1-2): 1 - 5.
42. Wong GK, et al. Long-term cognitive dysfunction in patients with traumatic subarachnoid hemorrhage: prevalence and risk factors. Acta Neurochir (Wien). 2012; 154(1): 105 - 111; discussion 111. DOI: 10.1007/s00701011-1198-8.

43. Eisenberg HM, et al. Initial CT finding in 753 patients with severe head injury: A report from the NIH Traumatic Coma Data Bank. J Neurosurg. 1990; 73(5): 688 - 698. DOI: 10.3171/jns.1990.73.5.0688.

44. Maas AI. et al. Prognostic value of computerized tomography scan characteristics in traumatic brain injury: results from the IMPACT study. J Neurotrauma. 2007; 24(2): 303 - 314. DOI: 10.1089/neu.2006.0033.

45. Lin TK, Tsai HC, Hsieh TC. The impact of traumatic subarachnoid hemorrhage on outcome: a study with grouping of traumatic subarachnoid hemorrhage and transcranial doppler sonography. J Trauma Acute Care Surg. 2012; 73(1): 131 - 136. DOI: 10.1097/TA.0b013e31824aff74.

46. Rosen DS, Macdonald RL. Subarachnoid hemorrhage grading scales: a systematic review. Neurocritical Care. 2005; 2(2): 110 - 118. DOI: 10.1385/NCC:2:2:110 (2005).

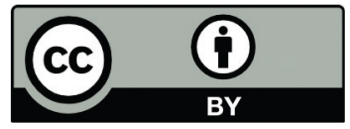

This work is licensed under a Creative Commons Attribution 